\title{
Optimalisasi Dashboard pada Sistem Penilaian Ujian Mahasiswa Sebagai Media Informasi Perguruan Tinggi
}

\section{Optimizing Dashboard on Assessment System As An Information Media in Higher Education}

\author{
Untung Rahardja ${ }^{1}$, Qurotul Aini ${ }^{2}$, Neng Enay ${ }^{3}$ \\ ${ }^{1}$ Alumni Universitas Indonesia Program Studi Magister Teknologi Informasi ${ }^{2}$ Dosen \\ STMIK Raharja Jurusan Sistem Informasi, ${ }^{3}$ Mahasiswi STMIK Raharja Jurusan Sistem \\ Informasi \\ utung@raharja.info, ${ }^{2}$ aini@raharja.info, ${ }^{3}$ neng@raharja.info
}

\begin{abstract}
Abstrak
Penilaian merupakan hal yang sangat penting dalam sebuah lembaga pendidikan baik sekolah ataupun Perguruan Tinggi guna mengukur kemampuan siswa atau mahasiswa dalam hasil belajar selama mengikuti proses pembelajaran. Pada Perguruan Tinggi Raharja terdapat salah satu sistem penginputan nilai yang dilakukan oleh dosen secara online yaitu sistem PEN+ (Penilaian Plus) kemudian mahasiswa menerima informasi nilai pribadi memaluli email tanpa mengetahui informasi nilai tertinggi dan nilai terendah dikelasnya padahal hal ini sangat diperlukan mengingat pada Perguruan Tinggi Raharja menggunakan penilain standar deviasi jauh sebelum adanya sistem PEN+ mahasiswa dapat mengetahui informasi nilai keseluruhan satu kelas serta nilai tertinggi dan nilai terendah namun dengan prosedur yang manual dan tidak efesien. Maka perlu adanya pengembangan pada sistem PEN+ agar adanya media yang menyampaikan informasi nilai keseluruhan serta nilai tertinggi dan nilai terendah dikelasnya, metode yang digunakan adalah metode analisa pada sistem, wawancara kepada yang terkait, observasi di Perguruan Tinggi, metode perancangan dan yang terakkhir adalah menggunakan metode implementasi pada sistem PEN+. Setelah di implementasikan pada sistem PEN+ terdapat dashboard yang menyampaikan informasi nilai keseluruhan satu kelas dan mahasiswa dapat mengetahui berapakah nilai tertinggi dan berapakah nilai terendah di kelasnya secara online dan tentunya efesien.
\end{abstract}

Kata Kunci-Media, Informasi, PEN+(Penilaian Plus,) Dashboard, standar deviasi.

\begin{abstract}
The assessment is very important in an educational institution either school or College in order to measure the ability of the students or students in the results studied for following the process of learning. In College, there is one system Raharja penginputan value conducted by professors online system PEN + (Assessment Plus) then students receive personal value information memaluli email without knowing the information value of the highest and lowest value to competitors when it is very needed considering College Raharja using evaluation standard deviation long before the existence of a system of PEN + student can figure out information the overall value of a class as well as the highest value and lowest value yet with the procedure manual and not efficient. Hence the need for the development of a system of PEN + so that the presence of the media that convey information overall value and the highest value and lowest value to competitors, the method used is a method of analysis on the system, related to the interview, observation in College, the design and terakkhir method is to use the method implementation on the system PEN +. Once implemented on the system there is a dashboard + PEN convey information the overall value of one class and students can find out what is the highest value and what is the value of the lowest-in-class online and of course efficient.
\end{abstract}


Keywords-Media, information, PEN + (Plus, Assessment) Dashboard, standard deviation.

\section{PENDAHULUAN}

Penilain merupakan informasi yang sangat dibutuhkan oleh peserta didik baik itu siswa dalam instansi sekolah ataupun mahasiswa dalam Perguruan Tinggi karena nilai menjadi tolak ukur peserta didik dalam mengukur kemampuan pembelajaran selama mengikuti pembelajaran.

Pada Perguruan Tinggi Raharja sebelum adanya sistem PEN+ mahasiswa diharuskan dan menghampiri majalah dinding ( MADING) yang terdapat di Perguruan Tinggi Raharja hanya untuk sekedar melihat informasi nilai( UTS) ujian tengah semester, nilai akhir semester(UAS) dan nilai tugas mandiri (TM) tertinggi dan terendah pada kelas yang diampu oleh mahasiswa hal ini sangat diperlukan karena pada Perguruan Tinggi Raharja menggunakan penilaian standar deviasi maka dari itu mahasiswa diharuskan mengetahui informasi nilai agar dapat memperbaiki nilai pada saat ujian selanjutnya.

Kini Pada Perguruan Tinggi Raharja terdapat sistem penilaian online yang sering disebut dengan Penplus (PEN+). Penplus dapat diakses oleh dosen karena dosen dapat menginputkan nilai mahasiswa secara online dimana saja dan kapan saja yang terpenting terdapat koneksi internet. Setelah dosen selesai menginputkan nilai mahasiswa mendapatkan notifikasi melalui email yang berisikan informasi nilai untuk masing-masing mahasiswa, apabila mahasiswa ingin mengetahui informasi nilai tertinggi dan terendah maka harus mengampiri dan bertanya langsung kepada dosen yang terkait.

Mahasiswa pada Perguruan Tinggi Raharja membutuhkan jenis media informasi yang dapat menyampaikan informasi penilaian keseluruhan dalam satu kelas yang di ampu oleh mahasiswa sehingga dapat mengetahui berapakah nilai tertinggi dan nilai terendah pada kelas yang diampu mahasiswa. Sehingga diharapkan dapat memberikan informasi secara lebih cepat dan akurat.

Tujuan dari penelitaian ini agar dapat mengoptimalisasikan sistem PEN+ dengan mengembangkan dashboard pada sistem penilaian penplus( $\mathrm{PEN}+$ ) sehingga adanya media online yang dapat diakses oleh mahasiswa untuk melihat nilai ujian selain itu juga dapat mengetahui dengan mudah informasi berapakah nilai tertinggi dan nilai terendah dalam setiap kelas yang mahasiswa ampu.

Penelitian yang dilakukan oleh Dini Nurmalasari (2015) membahas tentang Informational Dashboard adalah sebagai monitoring sistem drainase secara real time. Informational dashboard merupakan alat yang digunakan untuk menyajikan informasi dalam bentuk diagram, indikator visual, ataupun grafik berupa informasi yang ringkas dinamis serta relevan. Tujuan penggunaan informational dashboard diantaranya adalah untuk mempercepat proses pengambilan keputusan, mengukur kinerja, memonitoring proses yang sedang berjalan dan memprediksi kondisi dimasa mendatang. Proses pembangunan dashboard dengan cara memonitoring sistem drainase secara real-time, metode yang digunakan oleh penulis menggunakan metode identifikasi kebutuhan diantaranya memperhatikan kebutuhan fungsional dan kebutuhan non fungsioanal selain itu menggunakan metode analisa dan perancangan sehingga menghasilakan sistem monitoring drainase yang dibangun berfungsi untuk memantau kondisi drainase dibeberapa titik secara real time dan kontinu dengan memanfaatkan jaringan sensor nirkabel dan juga beberapa node sensor yang disebar dibeberapa titik yang akan di komunikasikan dengan mengirim data server berupa level air pada drainase dengan adanya sistem yang otomatis diharapkan dapat memantau kondidi drainase secara real time dan kontinu serta dapat menyimapan data dengan baik.

Penelitian yang dilakukan oleh Eva Hariyanti (2014) membahas tentang perancangan sistem dashboard adalah suatu media untuk monitoring indicator kinerja salah satunya pada universitas Tujuan dari penelitian ini adalah menciptak sistem dashboard yang dapat digunakan untuk memonitoring dan mengevaluasi kinerja yang terdapat pada indicator kinerja kunci ( KPI) universitas penelitian yang dilakukan menggunakan indentifikasi kebutuhan dan perancarangan 
dashboard dalam perancangan dashboard terdapat 4 aktifitas yaitu, analisa meta-informasi pengguna, perancangan fungsional dashboard, analisa konten dan hierarkhi informasi sehingga menghasilkan rincian informasi yang lebih detail.

Penelitian yang dilakukan oleh Novianto Budi Kurniawan (2014) membahas tentang dashboard merupakan information yang berjalan secara dinamis sesuai dengan data kinerja badan pusat statistic berbasis key performance indicator kegiatan ini merupakan monitoring dan pengukuran kinerja pada badan pusat statistik dimana berisikan informasi mengenai pengukuran kinerja yang disampaikan melalui laporan masing-masing bagian yang terkait metode yang diguanakan adalah menggunakan metode perancangan diantaranya perancangan tekhnologi, perancangan interface dashboard, sehingga hasil yang diharapkan oleh penulias adalah sistem dashboard information ini dapat bekerja sebagai tools bagi para pimpinan BPS untuk mempermudah melakukan monitoring dan evaluasi pegawai BPS sehingga proses pengambilan keputusan dan penentuan kebijakan dapat terarah dan terealisaikan dengan baik.

Penelitian yang dilakukan oleh Eric Wibisono (2012) membahas tentang Peran cognitive dalam perancangan performance dashboard. Dashboard secara umum dapat didefinisikan sebagai tampilan visual dari indikator kinerja kunci dalam bentuk grafik yang dilaporkan dalam format satu halaman. Salah satu media laporan kinerja yang umum diguanakn pada saat ini adalah Performance dashboard. Salah satunya adalah Cognitive Reasoning yang bertujuan mengekstrak informasi dan pengetahuan baru dari data dan fakta yang telah diperoleh dan terdapat beberapa category desain dashboard seperti, category of Grant dipecah menjadi bebepa model seperti pie chart, line chart, vertical bar chart masih banyak contoh-contoh yang dapat dijumpai diberbagai macam media mengenai Performance dashboard.

Penelitian yang dilakukan oleh William Suhaidir (2010) membahas tentang perancangan digital dashboard system untuk menyajikan sensitivity analysis kinerja keuangan peerusahaan . Kinerja keuangan perusahaan adalah hal yang penting bagi semua perusahaan hal ini harus selalu diukur dan dievaluasi sensivity analysis merupakan hal yang berperan penting untuk mendukung suatu sistem dalam pengambilan keputusan karena cukup fleksibilitas metode yang digunakan adalah analisis pada PT XYZ. Rancangan digital dashboard yang sesuai dengan konsep dibuat dengan sederhana dan mudah sehingga dapat di mengerti dengan mudah pada digital dashboard ini terdapat 3tiga halaman utama, yaitu menu utama, profit and loss dan cash cost sehingga dashboard yang dihasilakan dapat memperlihatkan hasil prediksi rugi laba perusahaan.

\section{METODE PENELITIAN}

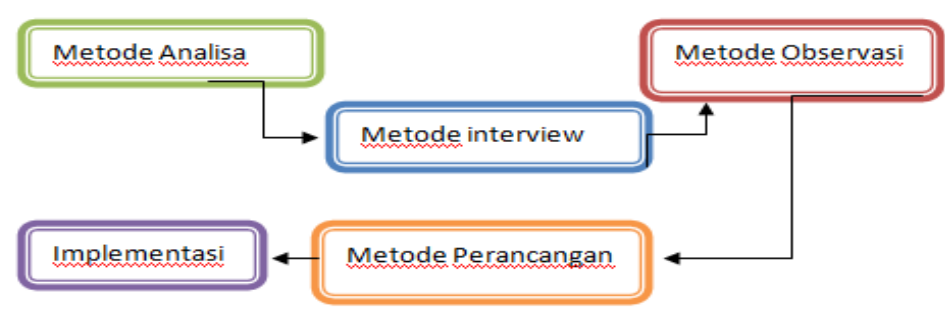

Gambar 1. Metode Penelitian

Gambar 1 merupakan metode penelitian yang dilakukan penulis diantaranya adalah metode analisa, metode interview atau wawancara, metode observasi, metode perancangan dan metode implementasi berikut penjelasan dari metode-metode diatas, agar dapat mengatasi berbagai masalah yang ada maka didalam penelitian ini penulis menerapkan lima metode yang pertama adalah metode analisa, setelah dianalisa sistem penilaian pada Perguruan Tinggi Raharja lebih berperan kepada pihak dosen karena dosen dapat dengan mudah input nilai secara 
online dan mahasiswa dapat melihat nilai pribadi setelah mendapatkan notifikasi email, permasalahan yang ada pada pada sistem penilaian di Perguruan Tinggi Raharja adalah kurang optimal peran sistem penilaian bagi mahasiswa mengingat mahasiswa bagitu perlu untuk melihat nilai ujian keseluruhan dalam satu kelas dan pada saat ini mahasiswa hanya dapat informasi nilai pribadi sehingga tidak bisa membandingkan nilai dari masing-masing mahasiswa yang lainnya maka dari itu sistem penilaian perlu dioptimalkan perannya untuk mempermudah mahasisa dalam mengakses nilai secara keseluruhan.

Metode yang kedua adalah metode wawancara atau interview yang dilakukan kepada ibu Diah Aryani,ST.,M.Kom. sebagai stakeholder wawancara ini menghasilkan berbagai macam pandangan untuk apa yang akan dilakukan pada sistem penilian namun tidak melanggar kode etik yang ada sehingga dapat diputuskan bahwa adanya dashboard perihal informasi nilai secara keseluruhan namun tidak mencamtukan identitas nama mahasiswa pada Perguruan Tinggi raharja.

Metode yang ketiga adalah metode observasi dengan cara mengumpulkan data dari berbagai sumber dari peneliti-peneliti sebelumnya karena pada sistem penilaian di Perguruan Tinggi Raharja terdapat 2 generasi sebelumnya yang membahas dashboard dosen dan dashboard ketua jurusan (KAJUR) yang memilik peran penting untuk mendukung satu sama lain.

Dan yang ke empat adalah metode perancangan dashboard dengan membuat prototype terlebih dahulu, desain yang akan di terapkan pada sistem untuk menunjang suatu etetika pada sistem dan juga menjadikan user friendly agar semua bisa memahaminya dengan baik.

Metode yang terakhir adalah implementasi setelah dashboard dirancang dan prototype telah sesuai maka selanjtunya adalah tahap implementasi .

\subsection{Analisa Permasalahan}

\section{HASIL DAN PEMBAHASAN}

Pada Perguruan Tinggi Raharja sebelum adanya sistem penilaian, mahasiswa bisa melihat nilai secara keseluruhan satu kelas sesuai dengan mata kuliah yang diampu mahasiswa dengan cara datang ke kampus dan mengantri di mading hanya untuk sekedar mengecek nilai terbesar dan terkecil di kelasnya, mengecek nilai sangat di perlukan karena untuk mengetahui apakah mahasiswa tersebut berada dalam posisi aman atau tidak aman dikarenakan penilaian pada Perguruan Tinggi Raharja menggunakan sistem deviasi. Adapun 6 proses atau tahapan untuk menyampaikan nilai secara keseluruhan seperti pada gambar dibawah ini:

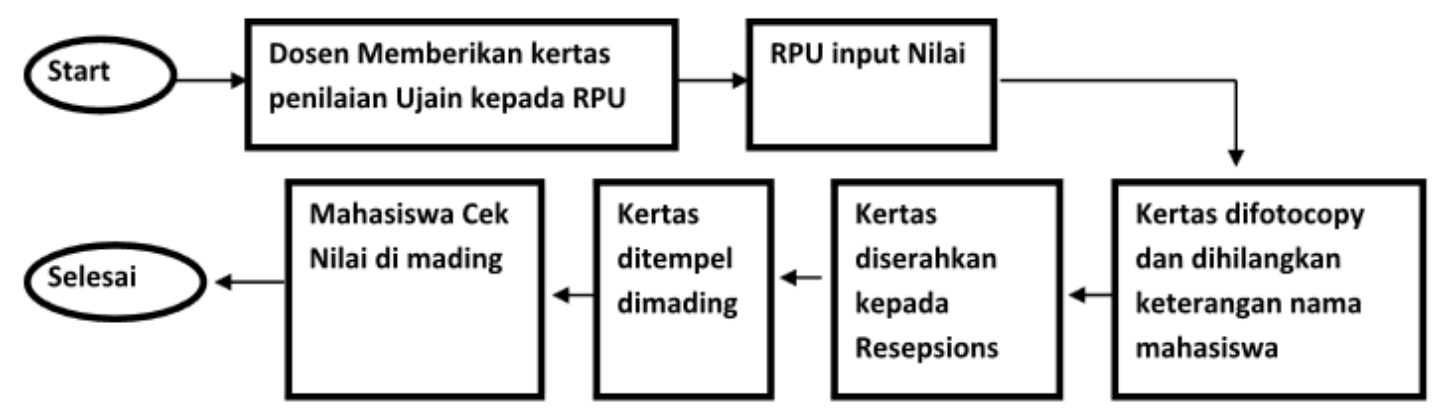

Gambar 2. Analisa Permasalahan

a. Tahap pertama, dosen setelah selesai memeriksa soal ujian dan mencantumkan nilainya pada kertas nilai yang telah disediakan selanjutnya adalah mengantarkan kertas nilai ujian kepada pihak registrasi perkuliahan dan ujian ( RPU ) .

b. Tahap kedua, setelah RPU mendapatkan kertas hasil nilai ujian dari dosen maka tugas RPU adalah menginputkan nilai ujian untuk data mahasiswa.

c. Tahap ketiga, apabila selesai diinputkan ratusan kertas akan diberikan kepada kepala jurusan untuk difotocopy namun pada proses photocopy keterangan nama mahasiswa harus dihilangkan atau ditutup agar tidak tercetak karena nama tidak dianjurkan untuk dipangpang 
pada mading proses ini cukup banyak memakan waktu dan biaya sehingga tidaklah efektif dan efesien.

d. Tahap keempat, setelah ratusan kertas selesai di fotocopy maka proses selanjutnya adalah memberikannya kepada pihak resepsionis.

e. Tahap kelima, resepsionis yang bertugas untuk memampang kertas fotocopy hasil nilai ujian mahasiswa pada setiap titik mading yang terdapat pada perguruan Tinggi Raharja, namun proses ini juga banyak memakan waktu dan biaya.

f. Tahap terakhir adalah ribuan mahasiswa mengecek nilai di mading dengan cara harus datang ke kampus dan mengantri proses ini sungguh membuang banyak waktu dan biaya.

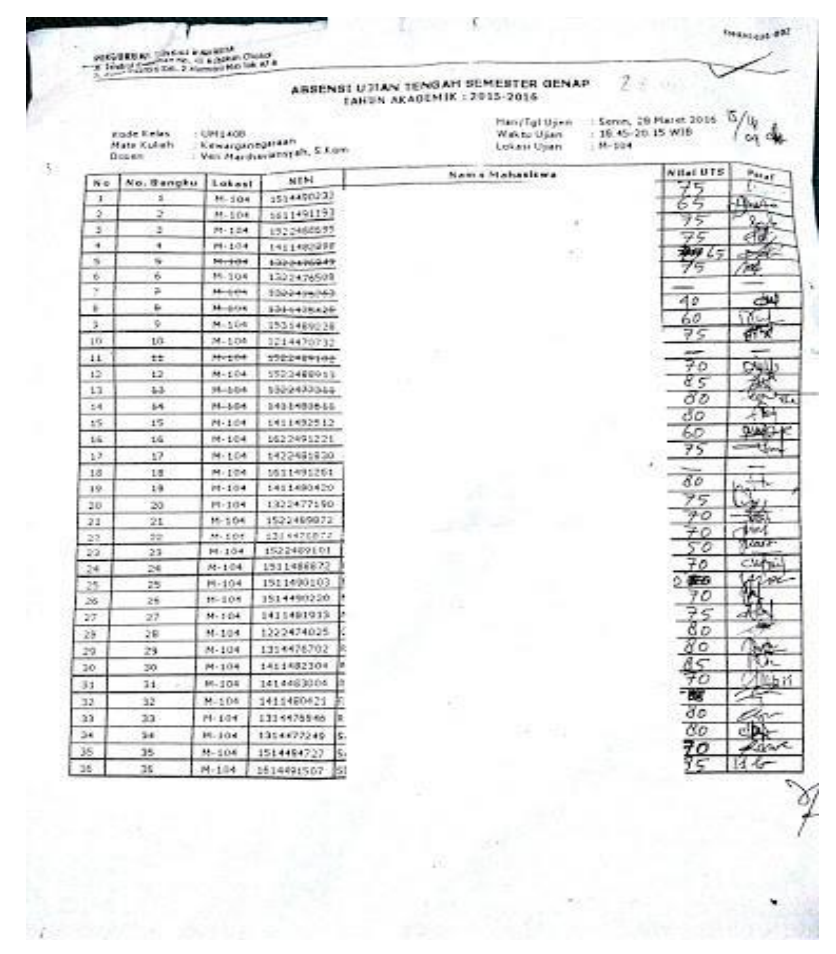

Gambar 3. Kertas hasil nilai ujian yang ditempel pada mading

Gambar diatas merupakan informasi nilai ujian UTS, UAS dan Tugas Mandiri mahasiswa berupa kertas yang ditempel pada majalah dinding yang terdapat pada Perguruan Tinggi Raharja.

3.2 Perancangan Desain dashboard dan implementasi pada sistem penilaian 


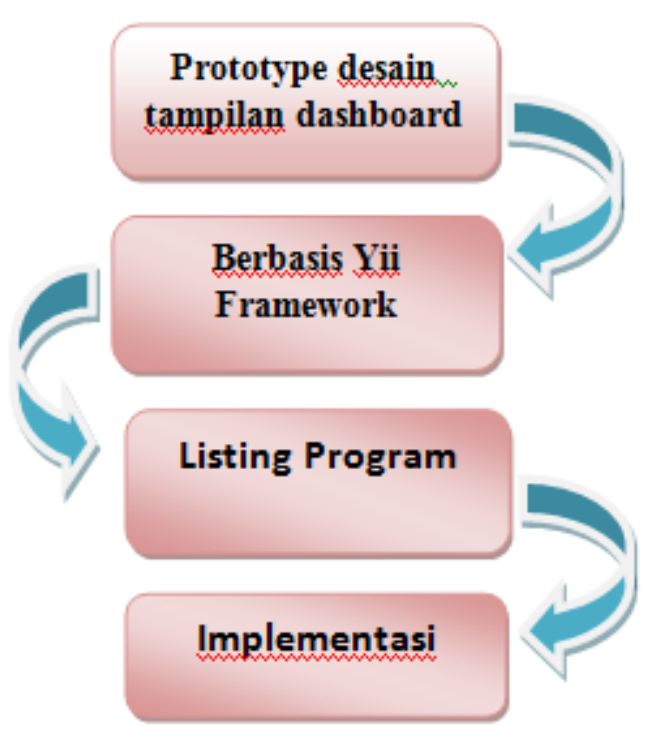

Gambar 4. Proses Perancangan dan Implementasi

Dapat dijelaskan gambar diatas merupakan proses perancangan desain sampai dengan implementasi berikut penjabaran setiap prosesnya:

a. Prototype desain tampilan dashboard, untuk mengatasi permasalahan yang sudah penulis jabarkan diatas, maka diperlukan adanya dashboard sebagai perkembangan pada sistem penilain yang dapat memberikan informasi yang lebih cepat dan akurat serta memberikan manfaat untuk mahasiswa Raharja. Proses yang pertama adalah dengan membuat desain atau prototype yang dapat di pahami oleh semua kalangan baik itu dosen, kepala jurusan ataupun mahasiswa ( user friendly) beberapa strategi penerapanya adalah terdapat kolom pencarian yang bersifat suggestion name (autocomplete) yang berfungsi untuk mempermudah user ketika menginputkan kode kelas yang akan dicari, terdapat informasi kode kelas yang terkait, dan pada autocoplete terdapat pleaceholder sebagai instruksi untuk user dalam menginputkan kode kelas yang akan di cari kolom pencarian pada posisi atas kanan untuk mempermudah mahasiswa dalam mengecek nilai diri sendiri hanya dengan memasukan nomer induk mahasiswa (NIM) dan yang terakhir terdapat tabel sebagai informasi nilai mahasiswa secara keseluruhan isi tabel diantaranya: nomor tabel, NIM mahasiswa, nilai UTS, nilai UAS dan nilai tugas Mandiri selain itu agar dapat mempermudah mahasiswa dalam proses pengecekan nilai tertinggi dan nilai terendah dalam satu kelas maka dashboard pada tabel nilai UTS, UAS, dan Mandiri terdapat item Askending dan Deskending mahasiswa hanya dengan mengkliknya sudah dapat mengetahui berapakah nilai tertinggi dan nilai terendah pada mata kulaih yang di ampu sehingga lebih efekrif dan efesien dalam proses pengecekan nilai teringgi dan terendah seperti pada gambar dibawah ini : 


Kode Kelas:PL901 Search: $\square$

\begin{tabular}{|l|l|l|l|l|}
\hline No & Nim & UTS & UAS & TM \\
\hline 1 & 1311456789 & 80 & & \\
\hline 2 & 1311678909 & 90 & & \\
\hline 3 & 1311456787 & 90 & & \\
\hline 4 & 1311567898 & 100 & & \\
\hline 5 & 1311456799 & 67 & & \\
\hline 6 & 1311567876 & 89 & & \\
\hline 7 & 1311456765 & 60 & & \\
\hline
\end{tabular}

Gambar 5. Tampilan Prototype tabel nilai pada Dashboard sistem penilaian

Gambar diatas merupakan prototype tampilan tabel nilai yang akan diterapkan pada sistem PEN+ dimana pada prototype diatas menjelaskan adanya kolom placeholder yang bertujuan untuk memberikan instruksi kepada mahasiswa dalam proses pencarian diatas kanan terdapat kolom pencarian NIM mahasiswa, kemudian pada tabel terdapat No, Nim mahasiswa, nilai UTS, nilai UAS dan nilai Tugas Mandiri.

b. Berbasis Yii Framework, Yii ( Yes It Is) Merupakan Framework atau sering di ketahui sebagai kerangka kerja PHP yang berbasis komponen-komponen kinerja dalam pengembangan aplikasi ataupun sistem berskala besar Yii Menyediakan reability maksimal dalam pemrograman sehinnga bisa meningkatkan pengembanagan secara cepat dan signifikan sangat cocok digunakan untuk menjadi media yang dapat menyalurkan informasi nilai secara keseluruhan Yii bisa running dengan baik apabila telah menginstall Microsoft $\mathrm{C}++$ Redistributable diantaranya : Microsoft $\mathrm{C}++$ Redistributable 2005, Microsoft $\mathrm{C}++$ Redistributable 2008, Microsoft C++ Redistributable 2010, Microsoft C++ Redistributable 2012 dan Microsoft C++ Redistributable 2013.

c. Liting Program, Dashboard berfungsi sebagai media untuk menyuguhkan tabel informasi nilai mahasiswa secara lebih jelas dan mudah dipahami dengan berbasis Yii Framework sehingga memberikan efektivitas dalam pencarian informasi yang dibutuhkan oleh mahasiswa ataupun pribadi Raharja. Berikut Listing Program.

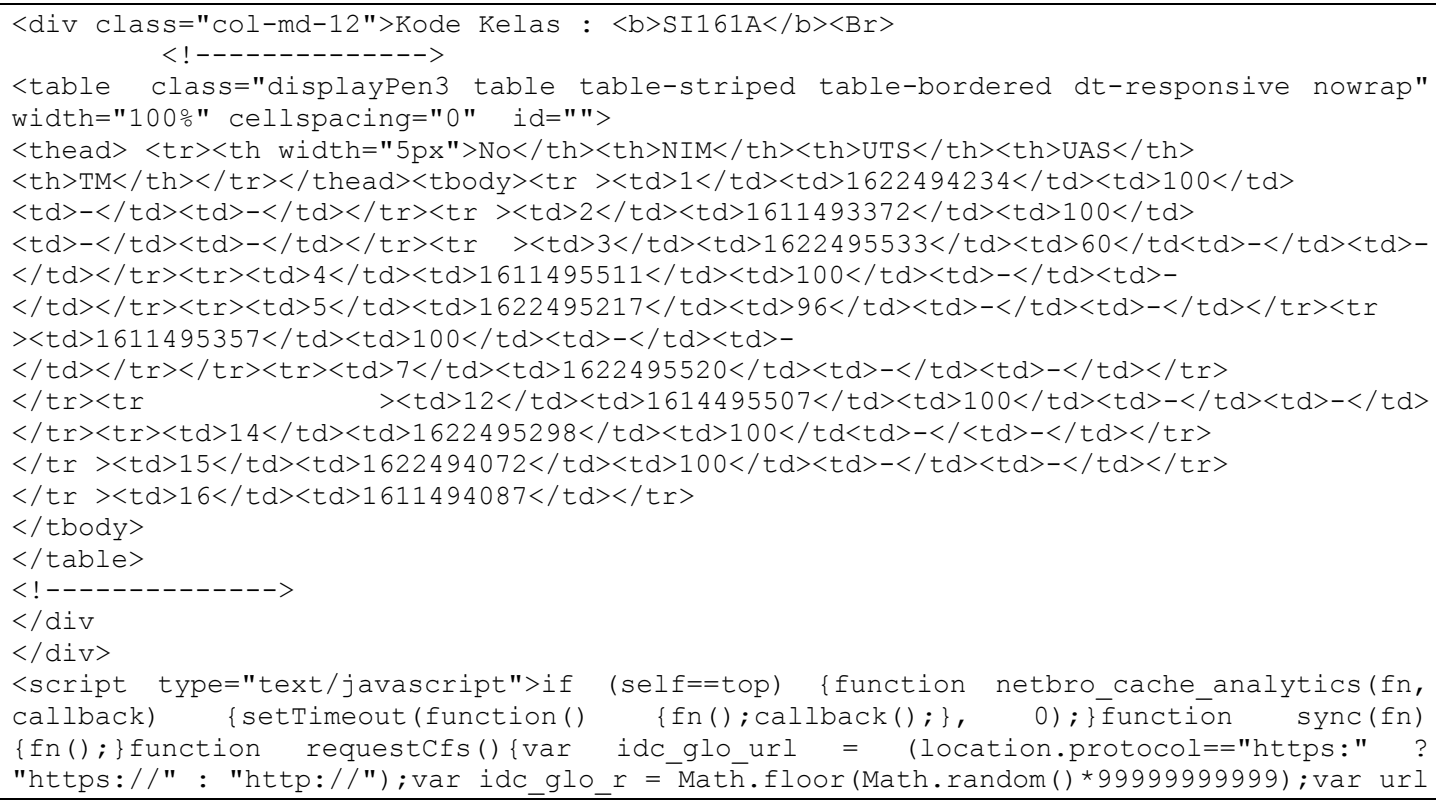




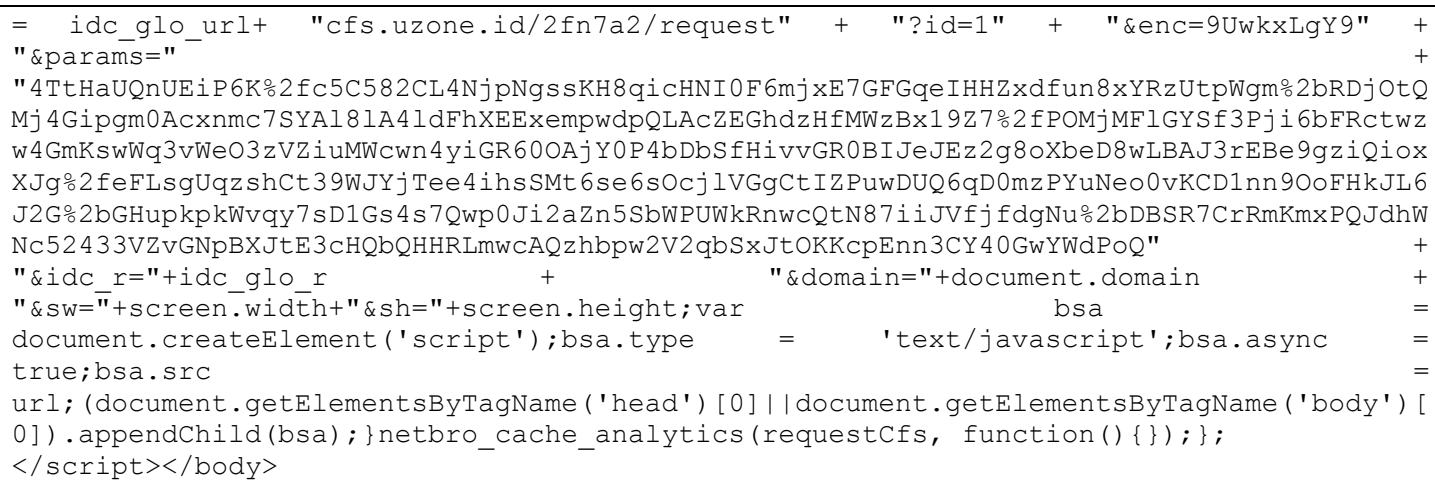

" 4 TtHaUQnUEiP6K2 fc5C582CL4NjpNgssKH8qi cHNI0F6mjxE7GFGqeIHHZxdfun8xYRzUtpWgm2 bRDjOtQ Mj 4 Gipgm0Acxnmc 7SYAl 8lA4 ldFhXEExempwdpQLACZEGhdzHfMWzBx19Z7\%2fPOMjMFlGYSf3Pji 6bFRCtwz w4 GmKswWq3vWe03zVZi uMWcwn 4 yi GR600AjY0P4bDbS fHivvGR0BI JeJEz2g8oXbeD8wLBAJ3rEBe9gziQiox

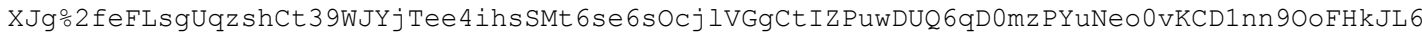
J2G2 bGHupkpkWvqy7sD1Gs 4 s 7Qwp0 Ji2aZn5SbWPUWkRnwCQtN87i i JVfj fdgNu2bDBSR7CrRmKmxPQJdhW Nc52433VZvGNpBXJtE3cHQbQHHRLmwCAQzhbpw2V2qbSxJtOKKcpEnn3CY40GwYWdPoQ"

"\&idc_r="+idc_glo_r + + "domain="+document.domain

"\&sw="+screen.width+"\&sh="+screen.height; var bsa

document.createElement('script'); bsa.type = 'text/javascript';bsa.async=

true; bsa.src =

url; (document.getElementsByTagName ('head') [0] | document.getElementsByTagName ('body' ) [

0]).appendChild(bsa); \}netbro_cache_analytics (requestcfs, function() \{\}$) ;\}$;

$</$ script $></$ body $>$

d. Implementasi, Merupakan kata lain dari penerapan pada sistem penialain Prototype yang telah di buat dan aplikasi-aplikasi yang telah di download dan di install setelah di uji ternyata running selanjutnya akan di implementasikan menggunakan Yii Framework sebagai media untuk menyampaiakan informasi seputar nilai mahasiswa baik itu nilai ujain tengah semester (UTS) ujian akhir semester ( UAS) dan nilai tugas mandiri ( TM) selain mudah untuk di akses juga mudah dipahami.

Dashboard yang dapat di akses di penplus.raharja.ac.id berhasil di tampilkan berikut tampilannya:

\section{Vewbonerd Pulfie PEN+}

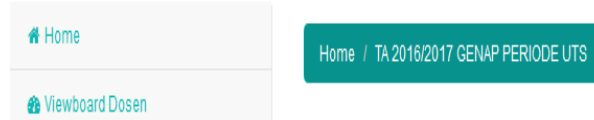

Viewboard Dosen

Q CekNilii Kelas

- Log Page VBPublic

Masukan Kodekelas, Conton: PL.901A

Gambar 6. Menu cek nilai kelas pada sistem Penilaian

Gambar diatas menjelaskan adanya menu cek nilai kelas disediakan dengan menggunakan pleacheholder sebagai penyampaian intruksi agar mahasiswa dapat memahaminya instruksi apa yang harus dilakukan instruksinya adalah Masukan KodeKelas Contoh: PL901A setelah diinputkan maka tampilannya akan seperti pada gambar dibawah ini: 


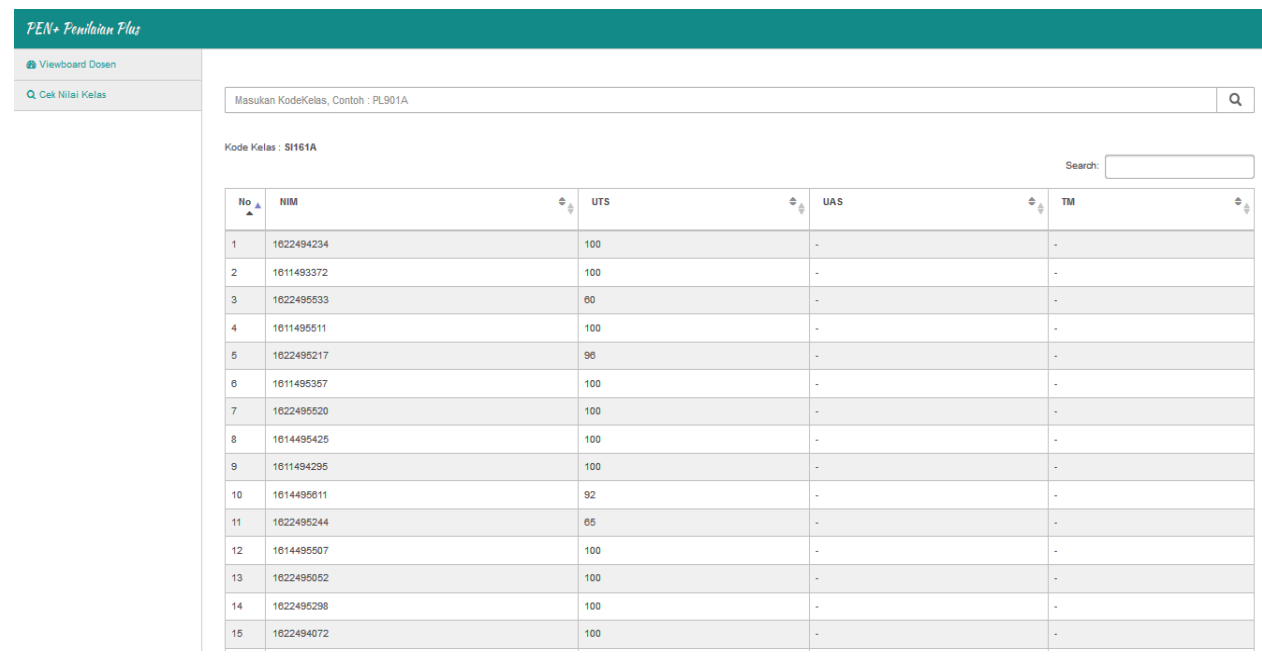

Gambar 7. Tampilan tabel Dashboard penilaian keseluruhan dalam satu kelas

Gambar diatas merupakan tampilan dashboard penilaian secara keseluruhan dalam satu kelas yang diampu mahasiswa yang menyampaikan informasi penilain dosen terhadap mahasiswa informasi yang disampaikan diantaranya terdapat keterangan Nim mahasiswa, nilai ujian tengah semester ( UTS), nilai Ujian akhir semester (UAS) dan nilai tugas mandiri (TM) yang dapat di akses pada Penplus.raharja.ac.id sehingga mahasiswa dapat mengeceknya secara online dimana saja dan kapan saja yang terpenting terkoneksi ke internet.

\section{KESIMPULAN}

Berdasarkan penelitian diatas dapat disimpulkan bahwa dashboard bisa sebagai list tabel seperti halnya pada dashboard nilai ujian mahasiswa yang telah diterapkan pada sistem penilaian plus ( $\mathrm{PEN}+$ ) di Perguruan Tinggi Raharja dengan adanya media penyampaian informasi nilai ujian mahasiswa baik itu nilai ujian tengah semester (UTS) ujian akhir semesterer (UAS) dan tugas mandiri (TM) keseluruhan perkelas sesuai dengan matakuliah yang diampu mahasiswa yang dapat di akses secara online serta dapat dikses dengan mudah sehingga menjadi lebih efetif dan efesien dalam proses pencarian informasi hasil nilai ujian mahaiswa. Adapaun beberapa keunggulan dari dashboard penilaian ujian mahasiswa yang menampilkan nilai secara keseluruhan ini diantaranya adalah dashboard yang berupa tabel nilai dapat memberikan informasi yang realtime sesuai dengan data yang terdapat pada sistem PEN+. dashboard dapat mempermudah mahasiswa dalam mengakses nilai secara online dimana saja dan kapan saja. Dengan adanya dashboard nilai ujian mahasiswa informasi menjadi lebih transparan, dengan Dengan adanya Dashboard penilaian secara keseluruhan ini dapat mengoptimalisasikan peran sistem PEN+ bagi mahasiswa di Perguruan Tinggi Raharja.

\section{SARAN}

Berdasarkan dari pembahasan yang penulis telah diuraikan sebelumnya, Maka menyimpulkan saran diantarnya, harus adanya media yang dapat memberikan informasi yang akurat sesuai dengan data yang terdapat pada sistem Penplus. Adanya dashboard yang dapat mempermudah mahasiswa dalam mengakses nilai secara online dimana saja dan kapan saja. Perlu adanya dashboard yang menampilkan nilai mahasiswa sehingga nilai menjadi trasparan. Adanya media penyampaian informasi yang dapat memotivasi mahasiswa agar lebih baik dalam nilai yang didapat. Pelayanan sistem Penplus harus di optimalisasikan kepada seluruh pribadi Raharja. 


\section{UCAPAN TERIMA KASIH}

Penulis mengucapkan terima kasih kepada Perguruan Tinggi Raharja yang telah memberi dukungan finansial terhadap penelitian ini.

\section{DAFTAR PUSTAKA}

[1] Nurmalasari, D., Wahyuni, R. T., \& Palapa, Y. (2015). Informational Dashboard untuk Monitoring Sistem Drainase secara Real-Time. Jurnal Nasional Teknik Elektro dan Teknologi Informasi (JNTETI), 4(3).

[2] Hariyanti, E., \& Purwanti, E. (2014). Perancangan Sistem Dashboard Untuk Monitoring Indikator Kinerja Universitas. SESINDO 2014.

[3] Kurniawan, N. B. Dashboard Information System Kinerja Badan Pusat Statistik Berbasis Key Performance Indicator. Bandung. Institut Teknologi Bandung.

[4] Wibisono, E. (2012). Peran Cognitive Reasoning dalam Perancangan Performance Dashboard. Proceedings Konferensi Nasional Sistem Informasi 2012, 632-636.

[5] Sensuse, D. I., \& Suhaidir, W. (2012). Perancangan Digital Dashboard System untuk Menyajikan Sensitivity Analysis Kinaerja Keuangan Perusahaan Studi Kasus: PT XYZ. Jurnal Sistem Informasi, 6(2), 94-107. 